\title{
Quercetin-Induced Cell Death in Human Papillary Thyroid Cancer (B-CPAP) Cells
}

\author{
Ergül Mutlu Altundağ, ${ }^{1,2}$ Tolga Kasacı, ${ }^{1}$ Ayşe Mine Yılmaz, ${ }^{1,2}$ Betül Karademir, ${ }^{1,2}$ \\ Semra Koçtürk, ${ }^{2,3}$ Yavuz Taga, ${ }^{1,2}$ and A. Süha Yalçınn ${ }^{1,2}$ \\ ${ }^{1}$ Department of Biochemistry, School of Medicine, Marmara University, Maltepe, 34854 Istanbul, Turkey \\ ${ }^{2}$ Genetic and Metabolic Diseases Research Center, Marmara University, Maltepe, 34854 Istanbul, Turkey \\ ${ }^{3}$ Department of Biochemistry, School of Medicine, Dokuz Eylül University, Inciralti, 35340 Izmir, Turkey \\ Correspondence should be addressed to A. Süha Yalçın; asyalcin@marmara.edu.tr
}

Received 4 September 2015; Revised 16 December 2015; Accepted 22 December 2015

Academic Editor: Gary L. Francis

Copyright (C) 2016 Ergül Mutlu Altundağ et al. This is an open access article distributed under the Creative Commons Attribution License, which permits unrestricted use, distribution, and reproduction in any medium, provided the original work is properly cited.

In this study, we have investigated the antiproliferative effect of quercetin on human papillary thyroid cancer cells and determined the apoptotic mechanisms underlying its actions. We have used different concentrations of quercetin to induce apoptosis and measured cell viability. Apoptosis and cell cycle analysis was determined by flow cytometry using Annexin V and propidium iodide. Finally, we have measured changes in caspase-3 and cleaved poly(ADP-ribose) polymerase (PARP) protein expression levels as hallmarks of apoptosis and Hsp90 protein expression level as a marker of proteasome activity in treated and control cells. Quercetin treatment of human papillary thyroid cancer cells resulted in decreased cell proliferation and increased rate of apoptosis by caspase activation. Furthermore, it was demonstrated that quercetin induces cancer cell apoptosis by downregulating the levels of Hsp90. In conclusion, we have shown that quercetin induces downregulation of Hsp90 expression that may be involved in the decrease of chymotrypsin-like proteasome activity which, in order, induces inhibition of growth and causes cell death in thyroid cancer cells. Thus, quercetin appears to be a promising candidate drug for Hsp90 downregulation and apoptosis of thyroid cancer cells.

\section{Introduction}

Thyroid cancer represents $1 \%$ of all malignancies with papillary thyroid carcinoma forming the majority of cases [1]. BCPAP is a papillary thyroid carcinoma cell line that is known to have BRAF V600E mutation. BRAF mutations occur in approximately $8 \%$ of human tumors and are also widespread in papillary thyroid cancer (36-69\%) [2,3]. Cancer therapy aimed at MAPK signaling utilizes selective inhibitors of RAF and MEK kinases as well as inhibitors of the Hsp90 [4-6]. Hsp90 is a chaperone protein necessary for survival under stress conditions which also regulates the stability and activity of oncogenic proteins [5]. It has been reported that inhibitors of Hsp90 may stimulate proteasomal degradation of mutant B-Raf proteins [6].

Protein degradation is an important aspect of chemotherapy since cancer cells may develop resistance via this pathway. Cancer cells have high proteasome activity compared to normal cells and the cancer cell degrades damaged proteins with its proteasome activity to develop resistance against chemotherapeutic drugs [5-7]. Many tumors show increased level of Hsps (Hsp90, Hsp70, Hsp60, and Hsp27) that promote tumor cell survival, growth, and metastasis $[7,8]$. These proteins are also involved in the oncogenic pathways of thyroid cancers. Since Hsp90 is known to interact with the proteasomal degradation system, it becomes important to consider its chemotherapeutic role. Thus Hsp90 inhibition may provide a new approach to thyroid cancer treatment.

On the other hand, studies in animals and humans have suggested that polyphenols, in particular the flavonoids, play an important role in regulating tumorigenesis $[7,9]$. Quercetin is a component of most eatable fruits and vegetables. It is a naturally occurring flavone that is present at high concentrations in different berries, onions, apples, and red wine [10]. Quercetin has selective antiproliferative 
and antitumor effects via apoptotic mechanisms on different human cancer cell lines [11]. In this study, we have used a papillary thyroid carcinoma cell line (B-CPAP) and investigated the antiproliferative effect of quercetin on these cells. We have determined the underlying apoptotic mechanisms which included caspase-3 activation, PARP cleavage, Hsp90 inhibition, and proteasomal degradation.

\section{Materials and Methods}

Propidium iodide (PI), quercetin (Q4951, purity > 95\%), MCA (methylcoumarin), suc-LLVY-MCA (succinyl-leucineleucine-valine-tyrosine-methylcoumarin), and ATP were purchased from Sigma-Aldrich (USA). WST-1 kit was from Roche Diagnostics (USA) and Hoechst 33342 stain from Life Technologies (Germany). Annexin V/PI was supplied by Millipore (USA) and formulated according to the manufacturer's instructions. Antibodies used were caspase-3 (Cat. \#9662, Cell Signaling, USA), cleaved PARP (Cat. \#9541, Cell Signaling, USA), Hsp90 (Cat. \#4874, Cell Signaling, USA), $\beta$-actin (Cat. \#4967, Cell Signaling, USA), and HRP-linked anti-rabbit IgG (Cat. \#7074, Cell Signaling, USA). Human papillary thyroid cancer cells (B-CPAP) were obtained from Deutsche Sammlung von Mikroorganismen und Zellkulturen (DSMZ, ACC 273).

2.1. Cell Viability Assay. Cells were cultured in RPMI-1640 medium (Biochrom, Germany) supplemented with $10 \%$ fetal bovine serum (Hyclone Laboratories, USA), 1\% L-glutamine, and $1 \%$ penicillin-streptomycin in a $5 \% \mathrm{CO}_{2}$ incubator at $37^{\circ} \mathrm{C}$. Cell viability was monitored using the WST-1 kit. Quercetin stock solution ( $500 \mathrm{mM}$ ) was prepared in dimethyl sulfoxide (DMSO) and stored at $-20^{\circ} \mathrm{C}$. It was diluted with RPMI-1640 medium before being used in different assays and the final concentration of DMSO was kept below $0.1 \%$. In viability experiments, $7 \times 10^{3}$ cells/well were seeded in 96 well plates in $100 \mu \mathrm{L}$ of culture media and were exposed to different concentrations of quercetin $(10-200 \mu \mathrm{M})$. After 24, 48 , or 72 hours, $10 \mu \mathrm{L}$ of WST-1 was added to each well and incubated for 2 hours at $37^{\circ} \mathrm{C}$. The plates were then shaken thoroughly on the shaker for $1 \mathrm{~min}$ and the absorbance of reporter substrate was measured at $420-480 \mathrm{~nm}$ using a microplate reader (Molecular Devices, USA).

\subsection{Detection of Apoptosis, Cell Cycle Analysis, and Chromatin} Staining. For detection of apoptosis, $0.5 \times 10^{6}$ cells were washed with PBS and ApopNexin FITC apoptosis detection kit (Millipore, USA) was used for analysis. In each assay $1 \times$ $10^{4}$ cells were measured. All experiments were performed in triplicate and results were assessed using the CellQuest program (Becton Dickinson, USA). For cell cycle analysis, $0.5 \times 10^{6}$ cells were harvested and centrifuged and the supernatant was discarded [12]. The pellet was suspended in PBS and 70\% cold ethanol. Cells were washed once with PBS, followed by incubation in PBS containing $50 \mathrm{mg} / \mathrm{mL}$ PI and $2 \mathrm{mg} / \mathrm{mL}$ DNase-free RNase A for $30 \mathrm{~min}$ at room temperature in the dark and they were analyzed on FACSCalibur flow cytometry system (Becton Dickinson, USA). For chromatin staining, cells were treated with quercetin for 24 hours and collected by centrifugation at $300 \times \mathrm{g}$ for $5 \mathrm{~min}$, fixed with $3.7 \%$ paraformaldehyde for $20 \mathrm{~min}$, and then stained with $10 \mu \mathrm{M}$ Hoechst 33342 dye for $15 \mathrm{~min}$. After washing with PBS, fluorescence was evaluated using a fluorescence microscope (Leica DFC 310 FX, Germany).

2.3. Western Blot Experiments and Proteasome Activity Measurements. For Western blotting and proteasome activity measurements, $1.8 \times 10^{6}$ cells were plated on $10 \mathrm{~cm}$ culture dishes. Cells were harvested and lysed in $200 \mu \mathrm{L}$ cold lysis buffer $(50 \mathrm{mM}$ Tris-HCl, pH 6.8, $15 \mathrm{mM}$ EDTA, $15 \mathrm{mM}$ $\mathrm{MgCl}_{2}, 50 \mathrm{mM} \beta$-glycerol, $150 \mu \mathrm{g} / \mathrm{mL}$ digitonin containing $1 \mathrm{mM}$ dithiothreitol, and $100 \mathrm{mM}$ phenylmethylsulfonyl fluoride). Samples were incubated on ice for $15 \mathrm{~min}$ and the supernatant was collected after centrifugation at $18,000 \times \mathrm{g}$ for $10 \mathrm{~min}$. Protein concentration was determined using BCA assay (Pierce Chemical, USA). Approximately $30 \mu \mathrm{g}$ of total proteins was loaded to each well and SDS-PAGE analysis was performed according to Laemmli [13]. Proteins were then transferred to nitrocellulose membranes by Turbo-Blot system (Bio-Rad Laboratories, USA). Membranes were blocked with $5 \%$ skimmed milk in Tris-buffered saline containing $0.1 \%$ Tween 20 and immunoblotted overnight at $4^{\circ} \mathrm{C}$ with the primary antibodies (Hsp90, caspase-3, and cleaved PARP) followed by the appropriate horseradish peroxidase-linked secondary antibody. Detection was performed using the West Pico chemiluminescent substrate kit (Thermo Scientific, USA) and the ChemiDoc MP System (Bio-Rad Laboratories, USA).

For proteasome activity, cells were incubated in cold $225 \mathrm{mM}$ Tris buffer ( $\mathrm{pH} 7.8$ ) containing $7.5 \mathrm{mM} \mathrm{MgOAc}$, $7.5 \mathrm{mM} \mathrm{MgCl}_{2}, 45 \mathrm{mM} \mathrm{KCl}$, and $1 \mathrm{mM}$ dithiothreitol, treated for $15 \mathrm{sec}$ in liquid nitrogen and then for $1 \mathrm{~min}$ in $40^{\circ} \mathrm{C}$ water bath (3 times). The lysates were centrifuged at $15,000 \times \mathrm{g}$ for $30 \mathrm{~min}$ at $4^{\circ} \mathrm{C}$. The fluorogenic peptide succinyl-leucineleucine-valine-tyrosine-methylcoumarin (suc-LLVY-MCA) was used as substrate at a concentration of $200 \mu \mathrm{M}$ to measure the chymotrypsin-like (CT-L) activity of the proteasome. To measure the activities of $20 \mathrm{~S}$ and $26 \mathrm{~S}$ proteasome, ATP was added into the reaction mixture. After $60 \mathrm{~min}$ of incubation at $37^{\circ} \mathrm{C}$, methylcoumarin liberation was measured with a fluorescence reader at $360 \mathrm{~nm}$ excitation and $485 \mathrm{~nm}$ emission. Results were calculated using free methylcoumarin (MCA) as standard [14].

2.4. Statistical Analysis. The significance of the effects on treatment groups was compared by analysis of variance (ANOVA) followed by Tukey's multiple comparison and Bonferroni posttests. $p$ values less than 0.05 were considered statistically significant.

\section{Results}

3.1. Effect of Quercetin on Cell Viability. Papillary thyroid cancer cells (B-CPAP) were treated with different concentrations of quercetin $(10,25,50,75,100,150$, and $200 \mu \mathrm{M})$ for 24,48 , and 72 hours to investigate the effect of quercetin 


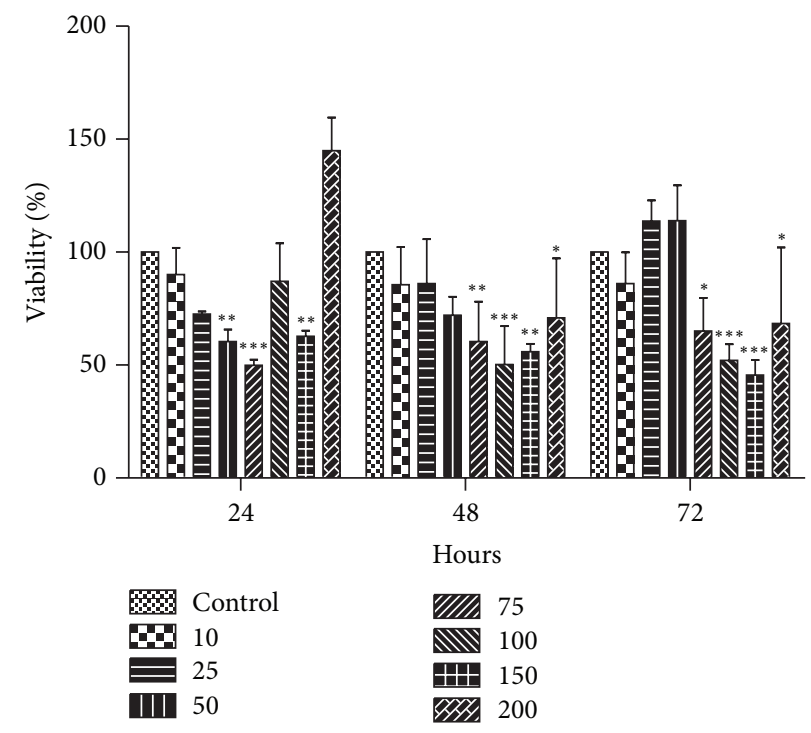

FIGURE 1: Effects of different concentrations of quercetin on cell viability. Cells were treated with different concentrations of quercetin (10$200 \mu \mathrm{M})$ for 24,48 , and 72 hours and cell viability was measured by WST-1 assay. All data points represent mean \pm SD, $n=3$. Differences between means and significance of the treatments were analyzed using ANOVA and Bonferroni posttest. ${ }^{*} p<0.05$ versus control, ${ }^{* *} p<0.01$ versus control, and ${ }^{* * *} p<0.001$ versus control.

on cell viability. As shown in Figure 1, quercetin treatment exerted both inhibitory and proliferative effects at different doses and time periods. A biphasic effect was observed after 24 hours. Although cell viability was decreased at 10, 25, 50, and $75 \mu \mathrm{M}$ concentrations compared to the control group, there was a significant proliferative effect at higher doses. These changes were less pronounced after 48 and 72 hours and were possibly masked by the proliferative effect and/or relatively short half-life of quercetin. In these preliminary experiments doubling time was observed to be 24 hours. Therefore, for further experiments, this time period and 10$75 \mu \mathrm{M}$ quercetin concentrations were chosen.

\subsection{Apoptosis, Cell Cycle Analysis, and Chromatin Staining.} Figure 2 shows changes in percentage of cells undergoing apoptosis 24 hours after quercetin treatment at 10, 25, 50, and $75 \mu \mathrm{M}$ compared to the control group. B-CPAP cells stained with Annexin-V and PI were followed by flow cytometry to determine the percentage of apoptotic cell death. The percentage of early (Q2) and late (Q3) apoptotic cells illustrated quercetin-induced increase in apoptosis. Our results showed that percentage of cells undergoing apoptosis was increased at all quercetin concentrations compared to the control group, but apoptosis rates were high and similar at 50 and $75 \mu \mathrm{M}$ concentrations (Figure 2(b)). The results of cell cycle analysis showed that percentage distribution of cells in different phases was not changed at low concentrations of quercetin, but at 50 and $75 \mu \mathrm{M}$ concentrations the number of cells in sub-G1 and S phase was increased, whereas the number of G0/G1 phase cells was decreased (Figure 3). Chromatin staining with Hoechst 33342 showed morphological changes such as cell surface blebs and formation of apoptotic bodies after treatment of cells with $50 \mu \mathrm{M}$ quercetin (Figure 4).
3.3. Western Blot Analysis. Figure 5 shows the results of Western blot analysis. Cleavage of caspase- 3 and PARP confirmed apoptosis at higher concentrations. When the cells were exposed to 50 and $75 \mu \mathrm{M}$ quercetin, caspase- 3 was cleaved from 35 to $19 \mathrm{kDa}$. Quercetin treatment downregulated the expression of Hsp90 in B-CPAP cells compared to controls. These results indicated that quercetin-induced cancer cell apoptosis may be related to the downregulation of Hsp90 levels.

3.4. Analysis of Proteasome Activity. We have also measured the chymotrypsin-like proteasome activity (CT-L) of $20 \mathrm{~S}$ and $26 \mathrm{~S}$ proteasome in the presence of quercetin (Figure 6). CT-L was inhibited significantly at $25-75 \mu \mathrm{M}$ quercetin. Inhibition of Hsp 90 by quercetin seems to be involved in the reduction of proteasome activity and apoptosis of B-CPAP cells.

\section{Discussion}

Differentiated thyroid carcinoma is the most common human endocrine malignancy of which papillary and follicular thyroid carcinomas are the two major variants [1]. Papillary thyroid cancers account for $80 \%$ of all thyroid cancers and have been characterized by alterations of one of several protein kinases [15]. Yin et al. [9] reported that flavonoids have potent antiproliferative activity in vitro against various human thyroid cancer cell lines and suggested that they might be used as therapeutic agents in the management of thyroid cancers. Although different groups studied apoptosis induced by quercetin in different cancer cell lines, the cellular and molecular mechanisms involved have not been fully elucidated $[16,17]$. 

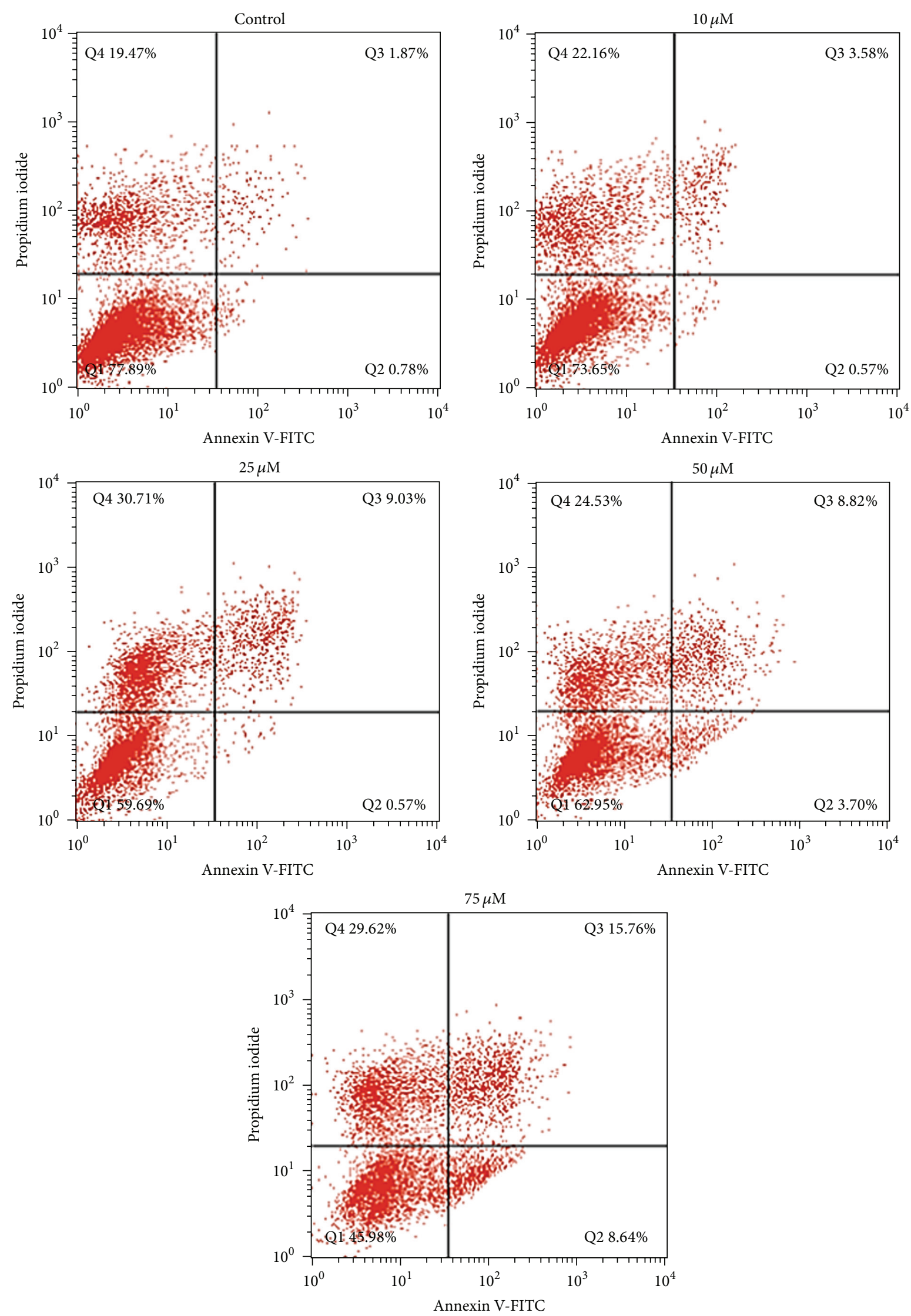

(a)

FIgURE 2: Continued. 


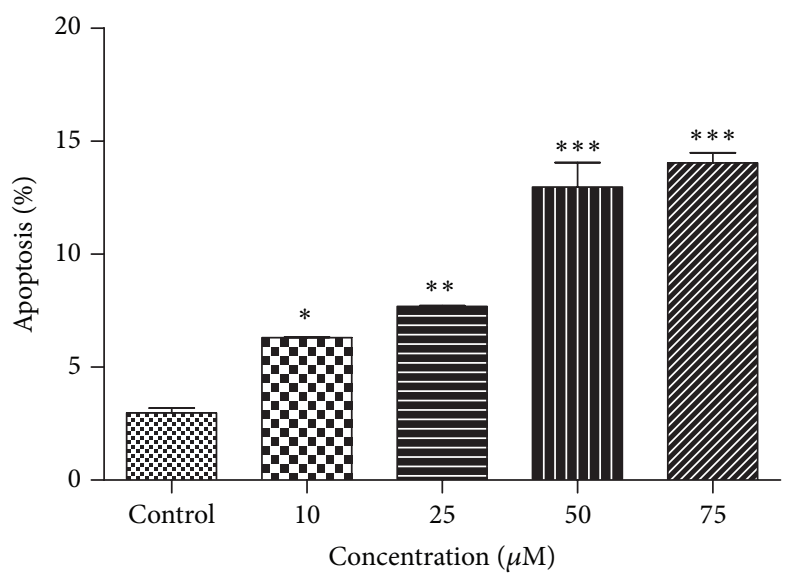

(b)

FIGURE 2: Flow cytometric analysis of quercetin-induced apoptotic cell death in B-CPAP cells. Cells were treated with different concentrations of quercetin $(10-75 \mu \mathrm{M})$ for $24 \mathrm{~h}$. Apoptosis was evaluated using Annexin V-FITC and PI staining followed by flow cytometry (a). Cells in the lower left quadrant (Annexin V-FITC-/PI-) are viable; those in the lower right quadrant (Annexin V-FITC+/PI-) are early apoptotic and those in the upper right quadrants (Annexin V-FITC+/PI+) are late apoptotic or necrotic. Apoptosis bar graphs (b) represent mean \pm $\mathrm{SD}, n=3$. Differences between means and significance of the treatments were analyzed using ANOVA and Tukey's multiple comparison test. ${ }^{*} p<0.05$ versus control, ${ }^{* *} p<0.01$ versus control, and ${ }^{* * *} p<0.001$ versus control.

In this study we report antiproliferative effect of quercetin on human papillary thyroid cancer cells. Our results showed that quercetin inhibits proliferation especially at 50 and $75 \mu \mathrm{M}$ concentrations. Quercetin concentration that significantly decreased papillary thyroid cancer cell viability was similar to those observed on other cancer cells, such as hepatoma [16], lung [17], colon [18], leukemia, and breast [19]. In a previous study, it was shown that quercetin inhibits growth of different thyroid cancer cell lines [20]. Additionally, quercetin was reported as a potent polyphenol inducing apoptosis in leukemia cell lines with IC50 values ranging between 8 and $33 \mu \mathrm{M}$ and AP50 values (the concentration at which $50 \%$ of cells undergo apoptosis) ranging between 19 and $50 \mu \mathrm{M}$ [21]. The antiproliferative effect of quercetin is believed to be exerted by producing cell cycle arrest in G1 phase [22]. In our study, we have shown that quercetin inhibited papillary thyroid cancer cell proliferation and triggered apoptosis at 50 and $75 \mu \mathrm{M}$ concentrations, but cells were arrested in the $S$ phase only at $75 \mu \mathrm{M}$ concentration.

Quercetin was found to have a differential effect on the cell cycle in different myeloid and lymphoid cell lines in the above-mentioned study [22]. Although their cell cycle data showed mainly G0/G1 arrest, some treatments arrested cells in S-phase and G2M. The mechanism of antiproliferative effect of quercetin in mammary and epidermoid cancer cells was investigated in a recent study by D'Archivio et al. [23]. These authors observed a biphasic effect similar to our findings and reported a dose dependent $S$ phase arrest at higher concentrations of quercetin.

Apoptosis is a morphologically distinct form of programmed cell death. Impairments in apoptosis can be associated with several disease states including cancer. Thus, induction of apoptosis in cancer cells is a potentially promising approach for cancer therapy [4]. Several studies, including ours, have shown that quercetin and other flavonoids have therapeutically relevant properties such as induction of apoptosis in tumor cells as well as antiviral, antioxidant, anti-inflammatory, and antiproliferative activities [9-11, 17, $21,24]$. To determine relevancy of these in vitro effects of polyphenols to their clinical use, it is essential to consider their bioavailability and whether these relatively high concentrations are achievable in plasma. It has been suggested that physiological concentrations of polyphenols and their metabolites in plasma will not exceed $10 \mu \mathrm{M}[25,26]$. Data on bioavailability of polyphenols is still limited, but there is evidence that quercetin obtained from plant products can result in micromolar concentrations in blood plasma [27]. It is also remarkable to note that published data on quercetin pharmacokinetics in humans suggest that a dietary supplement of 1-2 $\mathrm{g}$ of quercetin may result in plasma concentrations between 10 and $50 \mu \mathrm{M}$ and that these concentrations induce apoptosis and downregulate antiapoptotic proteins in vitro [28]. Apoptosis can be triggered by caspases. Caspases, represented by a family of cysteine proteases, are the key proteins that modulate the apoptotic response. Among them, caspase- 3 is a key protein of apoptotic mechanisms and the activated caspase- 3 is responsible for the morphological hallmarks of apoptosis, including DNA fragmentation and membrane blebbing [29]. We have measured the cleavage of caspase- 3 and PARP and observed that quercetin-induced cell death was accompanied by an increase in the activity of caspase-3 which stimulated the molecular cascade of apoptosis and DNA fragmentation. Heat shock proteins (Hsps) are extremely conserved and have different roles in principal cellular processes. Hsp90 is a molecular chaperone 

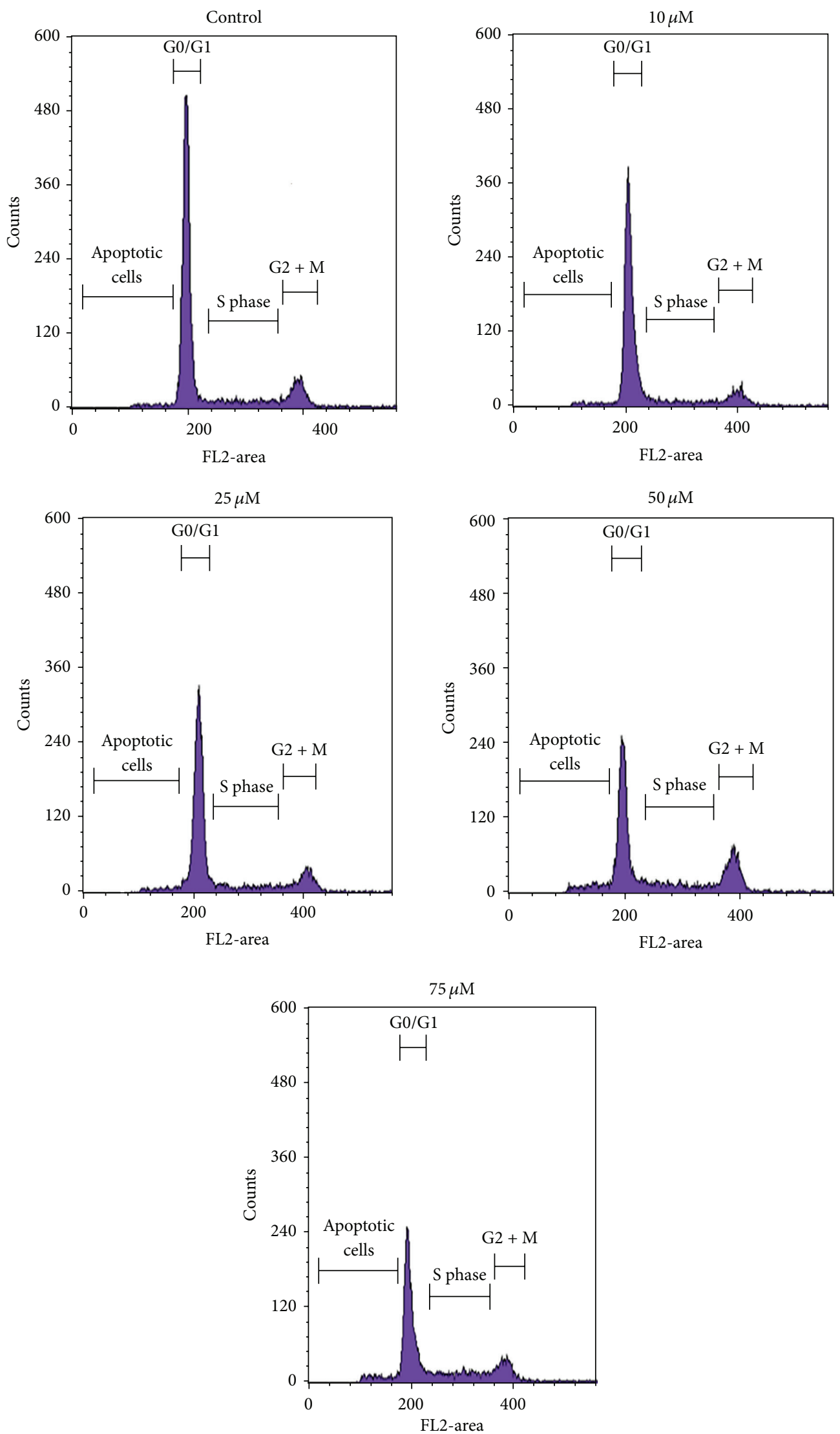

(a)

Figure 3: Continued. 


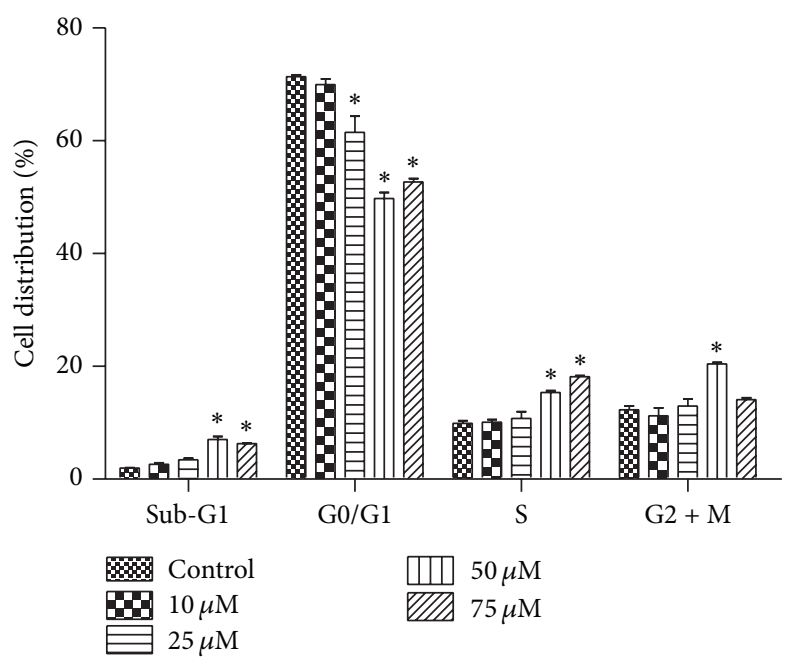

(b)

Figure 3: Flow cytometric analysis of quercetin-induced cell cycle distribution in B-CPAP cells. Cells were treated with different concentrations of quercetin $(10-75 \mu \mathrm{M})$ for 24 hours. Disruption of the cell cycle was analyzed by flow cytometry showing sub-G1 (apoptotic cells), G0/G1, S, and G2+M phases (a). Cell cycle bar graphs represent the percentage of cells within the different cell cycle phases (b). Differences between means and significance of the treatments were analyzed using ANOVA and Bonferroni posttest. Cell cycle bar graphs (b) represent mean $\pm \mathrm{SD}, n=3 .{ }^{*} p<0.05$ versus control.

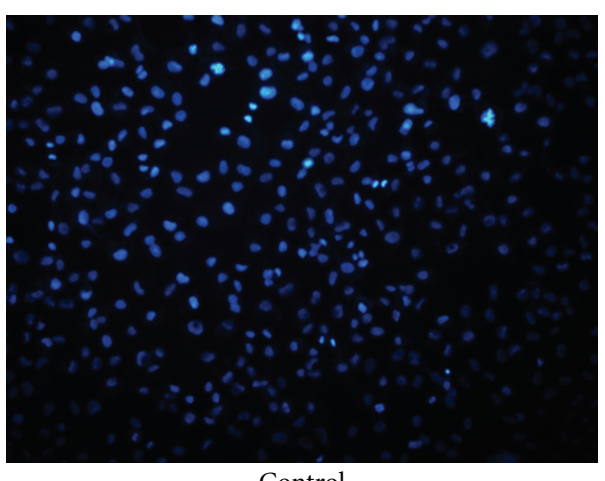

Control

(a)

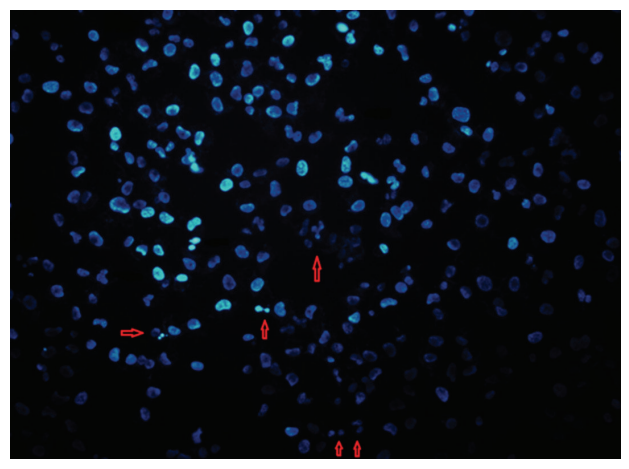

$50 \mu \mathrm{M}$ quercetin

(b)

Figure 4: Chromatin staining of B-CPAP cells with Hoechst 33342. Arrows indicate blebbing and chromatin condensation. Fluorescence microscope: Leica DFC 310 FX, Magnification: 40x.

and protects the organism from stress-induced cell injury. It has been reported to have a regulatory role on certain steps of the apoptotic cascade [5]. In this study, we have demonstrated that the ability of quercetin to induce apoptosis in B-CPAP cells was associated with its Hsp90 inhibitory activity. This effect might represent a mechanism by which polyphenolic dietary plant compounds may exert their anticancer effects.

Unlike normal cells, cancer cells have increased proteasomal activity that is essential for their survival and uninhibited proliferation [30, 31]. Proteasome activity is regulated via different regulators including Hsps. Among others, Hsp90 is mainly responsible for keeping proteins in a functional folded state. It also plays a role in the proteasomal degradation process. In addition to all these important functions, Hsp90 prevents protein aggregation [32]. In recent years, different polyphenols such as apigenin, epigallocatechin gallate, quercetin, and myricetin have been reported to act as proteasome inhibitors that induce cell death in cancer cells [33]. It was also reported that various fruit and vegetable extracts, particularly grape extract, are capable of inhibiting the proteasome activity and that this inhibition is associated with tumor cell apoptosis $[34,35]$. We have also observed that quercetin could significantly inhibit the proteasome activity in a concentration-dependent manner where chymotrypsinlike proteasomal activity was decreased at all concentrations of quercetin. Additionally, our data may provide a link 

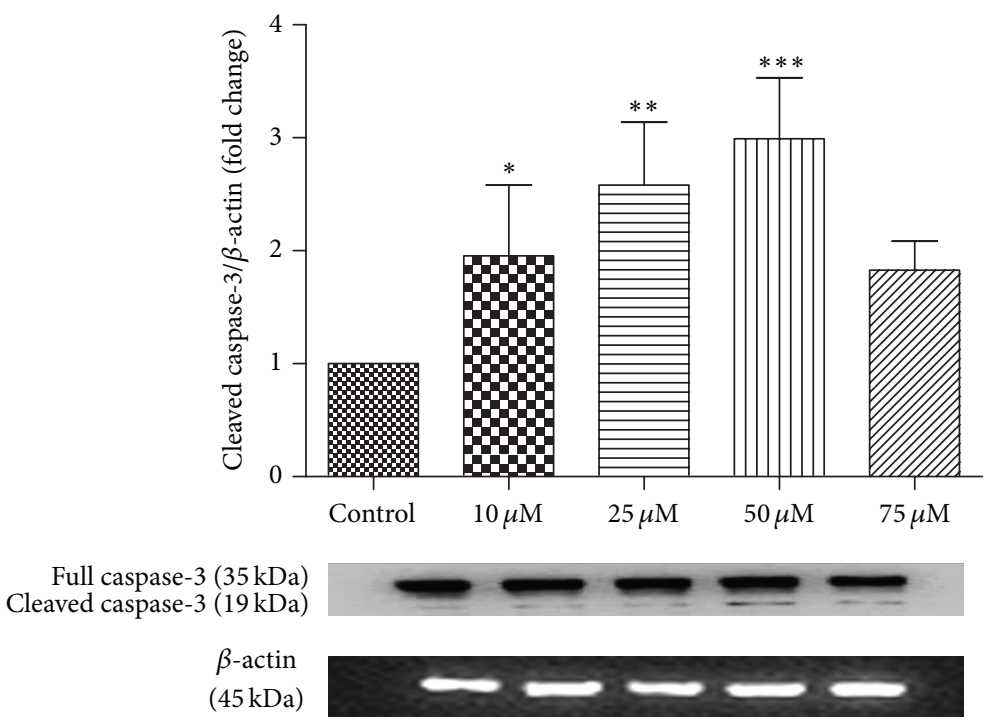

(a)
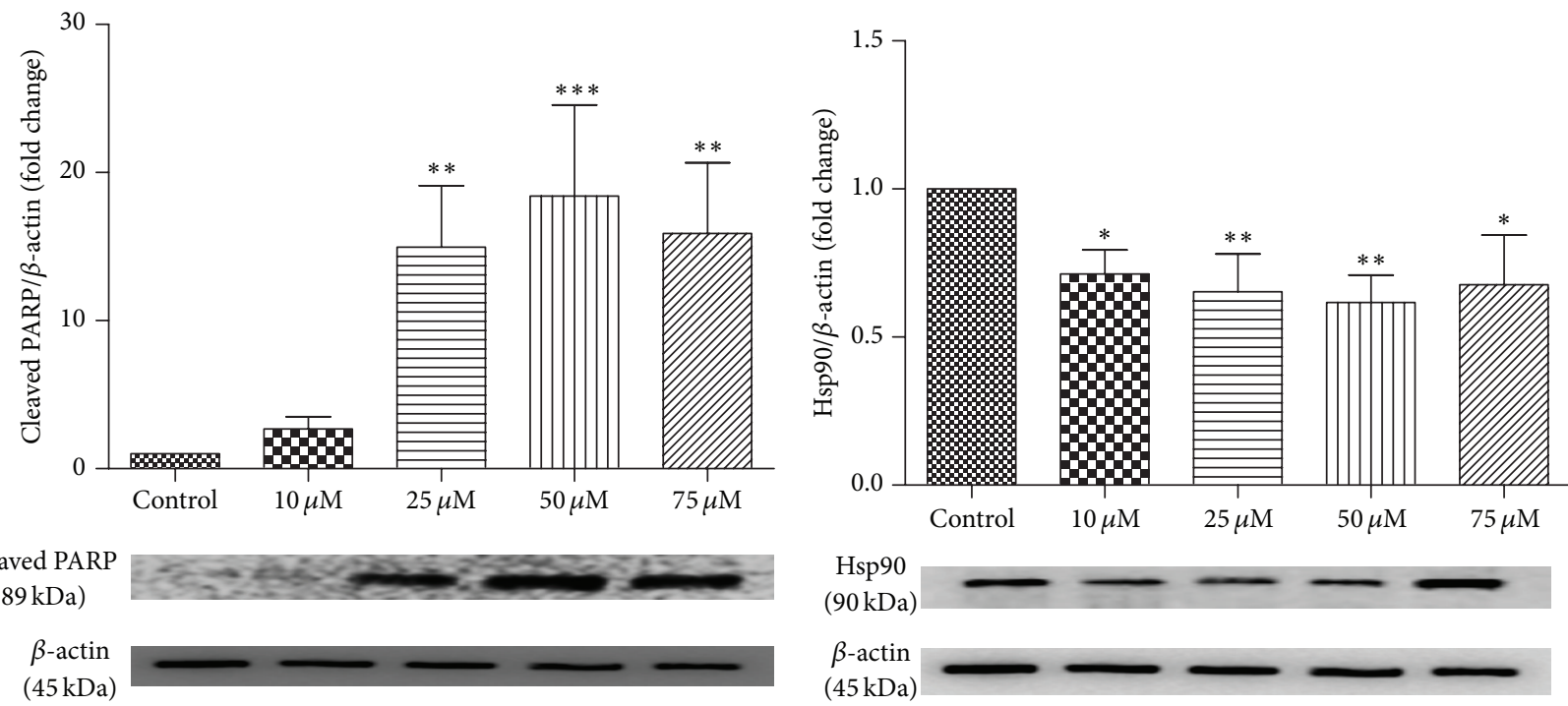

(b)

(c)

FIGURE 5: Western blot analysis of caspase-3 cleavage (a), PARP cleavage (b), and Hsp90 (c) protein expression levels after quercetin treatment of B-CPAP cells. Band intensity was analyzed by densitometry. Fold change of protein expression levels was calculated after bands were normalized to $\beta$-Actin. Differences between means and significance of the treatments were analyzed using ANOVA and Bonferroni posttest. Bar graphs represent mean $\pm \mathrm{SD}, n=3 .{ }^{*} p<0.05$ versus control, ${ }^{* *} p<0.01$ versus control, and ${ }^{* * *} p<0.001$ versus control.

between Hsp90 downregulation and proteasome inhibition through increased protein aggregation.

\section{Conclusion}

Although research in recent years has generated new targeted therapies in thyroid cancer, a gap remains in the treatment of recurrent papillary cancers not amenable to operative resection. We have shown that quercetin downregulates the expression of Hsp90 and decreases chymotrypsin-like proteasome activity and that these effects are related to inhibition of growth and caspase dependent apoptotic cell death in papillary thyroid cancer cells. It is hypothesized that these effects lead to certain stress conditions in cells which trigger the apoptotic cell death mechanism via caspase-3 activation and PARP cleavage. Thus, Hsp90 inhibition appears to be an important approach for thyroid cancer drug development. However, the molecular mechanism of the antiproliferative and apoptotic effects of Hsp90 remains to be determined.

\section{Conflict of Interests}

The authors confirm that this paper's content has no conflict of interests. 


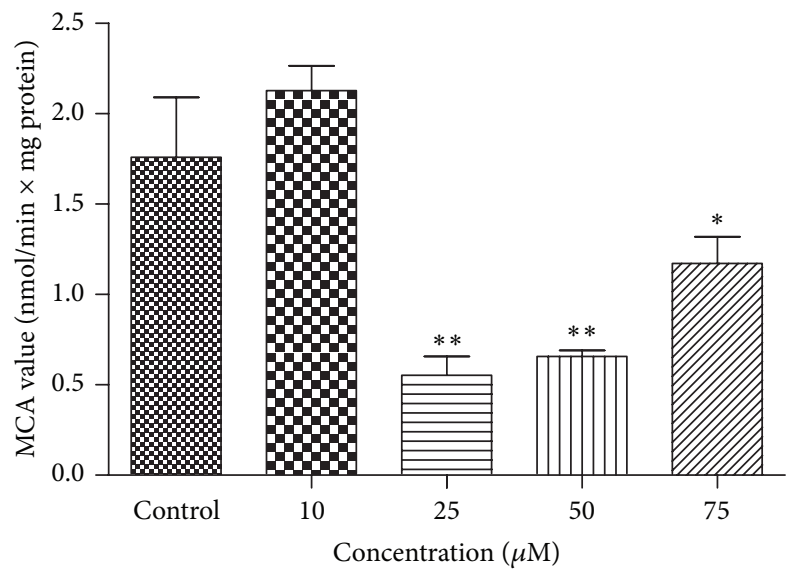

FIGURE 6: Determination of proteasome activity after quercetin treatment of B-CPAP cells. The fluorogenic peptide suc-LLVYMCA was used as substrate to measure chymotrypsin-like (CT-L) activities of $20 \mathrm{~S}$ and $26 \mathrm{~S}$ proteasome. Differences between means and significance of the treatments were analyzed using ANOVA and Bonferroni posttest. Bar graphs represent mean $\pm \mathrm{SD}, n=3$. ${ }^{*} p<0.05$ versus control, ${ }^{* *} p<0.01$ versus control.

\section{Authors' Contribution}

Ergül Mutlu Altundağ and Tolga Kasacı contributed equally to this work.

\section{Acknowledgments}

This study was supported by Marmara University Research Council (SAG-C-TUP-130313-0063) and The Scientific and Technological Research Council of Turkey (TUBITAK110S281).

\section{References}

[1] L. Enewold, K. Zhu, E. Ron et al., "Rising thyroid cancer incidence in the United States by demographic and tumor characteristics 1980-2005," Cancer Epidemiology Biomarkers and Prevention, vol. 18, no. 3, pp. 784-791, 2009.

[2] E. Halilovic and D. B. Solit, "Therapeutic strategies for inhibiting oncogenic BRAF signaling," Current Opinion in Pharmacology, vol. 8, no. 4, pp. 419-426, 2008.

[3] H. Davies, G. R. Bignell, C. Cox et al., "Mutations of the BRAF gene in human cancer," Mutations the Nature, vol. 417, pp. 949954, 2002.

[4] A. S. Sreedhar and P. Csermely, "Heat shock proteins in the regulation of apoptosis: new strategies in tumor therapy-a comprehensive review," Pharmacology and Therapeutics, vol. 101, no. 3, pp. 227-257, 2004.

[5] R. Bagatell and L. Whitesell, "Altered Hsp90 function in cancer: a unique therapeutic opportunity," Molecular Cancer Therapeutics, vol. 3, no. 8, pp. 1021-1030, 2004.

[6] O. M. Grbovic, A. D. Basso, A. Sawai et al., "V600E B-Raf requires the Hsp90 chaperone for stability and is degraded in response to Hsp90 inhibitors," Proceedings of the National Academy of Sciences of the United States of America, vol. 103, no. 1, pp. 57-62, 2006.
[7] K. Anand, P. Asthana, A. Kumar, R. K. Ambasta, and P. Kumar, "Quercetin mediated reduction of angiogenic markers and chaperones in DLA-induced solid tumours," Asian Pacific Journal of Cancer Prevention, vol. 12, no. 11, pp. 2829-2835, 2011.

[8] J.-W. Park, M. W. Yeh, M. G. Wong et al., "The heat shock protein 90-binding geldanamycin inhibits cancer cell proliferation, down-regulates oncoproteins, and inhibits epidermal growth factor-induced invasion in thyroid cancer cell lines," Journal of Clinical Endocrinology and Metabolism, vol. 88, no. 7, pp. 33463353, 2003.

[9] F. Yin, A. E. Giuliano, and A. J. Van Herle, "Growth inhibitory effects of flavonoids in human thyroid cancer cell lines," Thyroid, vol. 9, no. 4, pp. 369-376, 1999.

[10] S. H. Häkkinen, S. O. Kärenlampi, I. M. Heinonen, H. M. Mykkänen, and A. R. Törronen, "Content of the flavonols quercetin, myricetin, and kaempferol in 25 edible berries," Journal of Agricultural and Food Chemistry, vol. 47, no. 6, pp. 2274-2279, 1999.

[11] B. Csokay, N. Prajda, G. Weber, and E. Olah, "Molecular mechanisms in the antiproliferative action of quercetin," Life Sciences, vol. 60, no. 24, pp. 2157-2163, 1997.

[12] C. Riccardi and I. C. Nicoletti, "Analysis of apoptosis by propidium iodide staining and flow cytometry," Nature Protocols, vol. 1, no. 3, pp. 1458-1461, 2006.

[13] U. K. Laemmli, "Cleavage of structural proteins during the assembly of the head of bacteriophage T4," Nature, vol. 227, no. 5259, pp. 680-685, 1970.

[14] B. Catalgol, B. Wendt, S. Grimm, N. Breusing, N. K. Özer, and T. Grune, "Chromatin repair after oxidative stress: role of PARP-mediated proteasome activation," Free Radical Biology and Medicine, vol. 48, no. 5, pp. 673-680, 2010.

[15] M. Santoro and F. Carlomagno, "Drug insight: small-molecule inhibitors of protein kinases in the treatment of thyroid cancer," Nature Clinical Practice Endocrinology and Metabolism, vol. 2, no. 1, pp. 42-52, 2006.

[16] A. B. Granado-Serrano, M. A. Martín, L. Bravo, L. Goya, and S. Ramos, "Quercetin induces apoptosis via caspase activation, regulation of Bcl-2, and inhibition of PI-3-kinase/Akt and ERK pathways in a human hepatoma cell line (HepG2)," Journal of Nutrition, vol. 136, no. 11, pp. 2715-2721, 2006.

[17] T. T. T. Nguyen, E. Tran, T. H. Nguyen, P. T. Do, T. H. Huynh, and H. Huynh, "The role of activated MEK-ERK pathway in quercetin-induced growth inhibition and apoptosis in A549 lung cancer cells," Carcinogenesis, vol. 25, no. 5, pp. 647-659, 2004.

[18] M. J. Van Erk, P. Roepman, T. R. Van Der Lende et al., "Integrated assessment by multiple gene expression analysis of quercetin bioactivity on anticancer-related mechanisms in colon cancer cells in vitro," European Journal of Nutrition, vol. 44, no. 3, pp. 143-156, 2005.

[19] N. Gulati, B. Laudet, V. M. Zohrabian, R. Murali, and M. Jhanwar-Uniyal, "The antiproliferative effect of Quercetin in cancer cells is mediated via inhibition of the PI3K-Akt/PKB pathway," Anticancer Research, vol. 26, no. 2, pp. 1177-1181, 2006.

[20] H. J. Kang, Y.-K. Youn, M.-K. Hong, and L. S. Kim, "Antiproliferation and redifferentiation in thyroid cancer cell lines by polyphenol phytochemicals," Journal of Korean Medical Science, vol. 26, no. 7, pp. 893-899, 2011.

[21] A. A. Mahbub, C. L. Le Maitre, S. L. Haywood-Small, G. J. McDougall, N. A. Cross, and N. Jordan-Mahy, "Differential effects of polyphenols on proliferation and apoptosis in human 
myeloid and lymphoid leukemia cell lines," Anti-Cancer Agents in Medicinal Chemistry, vol. 13, no. 10, pp. 1601-1613, 2013.

[22] M. Yoshida, M. Yamamoto, and T. Nikaido, "Quercetin arrests human leukemic T-cells in late G1 phase of the cell cycle," Cancer Research, vol. 52, no. 23, pp. 6676-6681, 1992.

[23] M. D’Archivio, C. Filesi, R. Varì, B. Scazzocchio, and R. Masella, "Bioavailability of the polyphenols: status and controversies," International Journal of Molecular Sciences, vol. 11, no. 4, pp. 1321-1342, 2010.

[24] L. Zhang, "Curcumin induces autophagic cell death in human papillary thyroid carcinoma BCPAP cells," in Proceedings of the 10th Asia and Oceania Thyroid Association Congress, Bali, Indonesia, October 2012.

[25] C. Manach, A. Scalbert, C. Morand, C. Rémésy, and L. Jiménez, "Polyphenols: food sources and bioavailability," The American Journal of Clinical Nutrition, vol. 79, no. 5, pp. 727-747, 2004.

[26] P. C. H. Hollman, J. M. P. van Trijp, M. N. C. P. Buysman et al., "Relative bioavailability of the antioxidant flavonoid quercetin from various foods in man," FEBS Letters, vol. 418, no. 1-2, pp. 152-156, 1997.

[27] S. Ramos, "Effects of dietary flavonoids on apoptotic pathways related to cancer chemoprevention," Journal of Nutritional Biochemistry, vol. 18, no. 7, pp. 427-442, 2007.

[28] X. Wang, "The expanding role of mitochondria in apoptosis," Genes \& Development, vol. 15, no. 22, pp. 2922-2933, 2001.

[29] J. M. Eckl and K. Richter, "Functions of the Hsp90 chaperone system: lifting client proteins to new heights," International Journal of Biochemistry and Molecular Biology, vol. 4, no. 4, pp. 157-165, 2013.

[30] P. Bozaykut, N. K. Özer, and B. Karademir, "Regulation of protein turnover by heat shock proteins," Free Radical Biology and Medicine, vol. 77, pp. 195-209, 2014.

[31] S. Messaoudi, J. F. Peyrat, J. D. Brion, and M. Alami, "Recent advances in Hsp90 inhibitors as antitumor agents," Anti-Cancer Agents in Medicinal Chemistry, vol. 8, no. 7, pp. 761-782, 2008.

[32] M. Kästle and T. Grune, "Interactions of the proteasomal system with chaperones: protein triage and protein quality control," Progress in Molecular Biology and Translational Science, vol. 109, pp. 113-160, 2012.

[33] D. Chen, K. G. Daniel, M. S. Chen, D. J. Kuhn, K. R. LandisPiwowar, and Q. P. Dou, "Dietary flavonoids as proteasome inhibitors and apoptosis inducers in human leukemia cells," Biochemical Pharmacology, vol. 69, no. 10, pp. 1421-1432, 2005.

[34] I. Ayesha, N. Bindu, S. Shulagna, M. Chandana, B. Mehrajuddin, and M. Raghunath, "Proteasome inhibitory potential of commonly consumed dietary ingredients," International Journal of Food and Nutrition Science, vol. 1, no. 4, pp. 27-31, 2012.

[35] M. S. Chen, D. Chen, and Q. P. Dou, "Inhibition of proteasome activity by various fruits and vegetables is associated with cancer cell death," In Vivo, vol. 18, no. 1, pp. 73-80, 2004. 


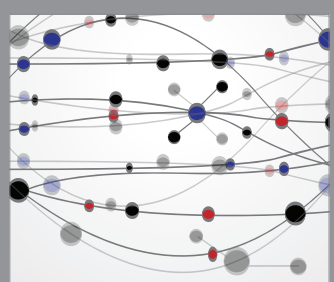

The Scientific World Journal
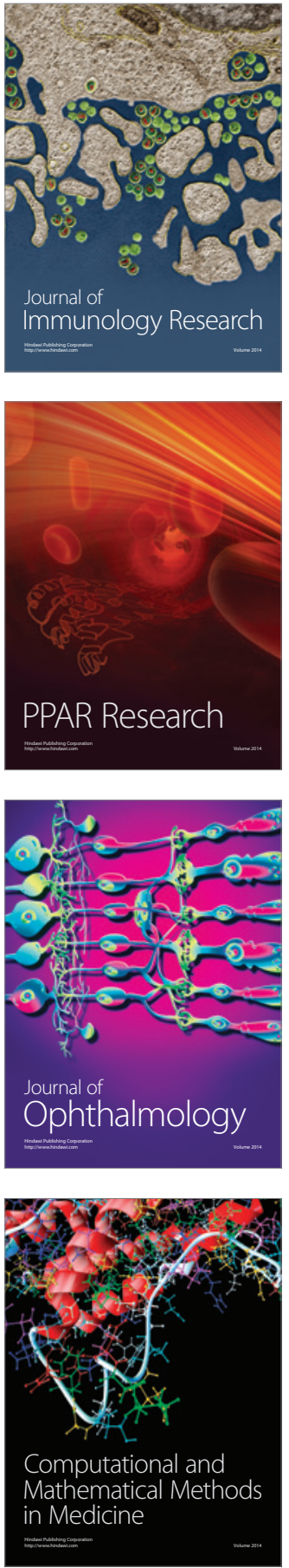

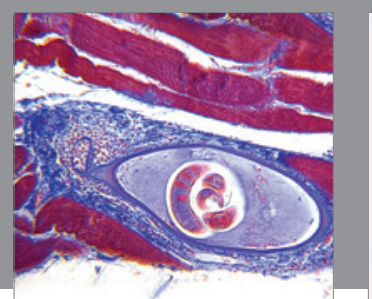

Gastroenterology Research and Practice

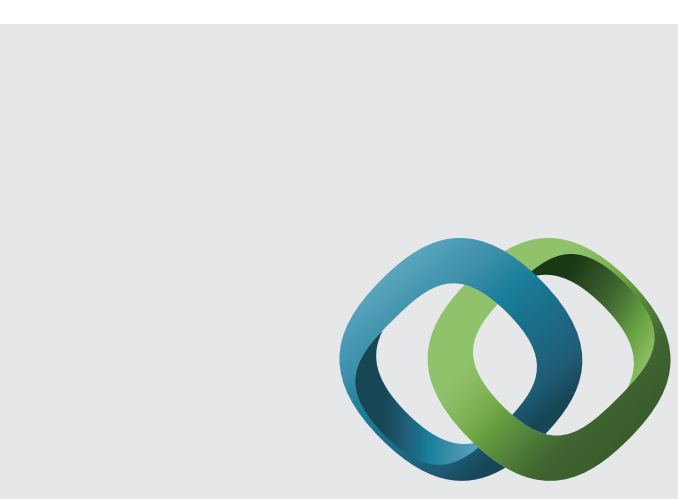

\section{Hindawi}

Submit your manuscripts at

http://www.hindawi.com
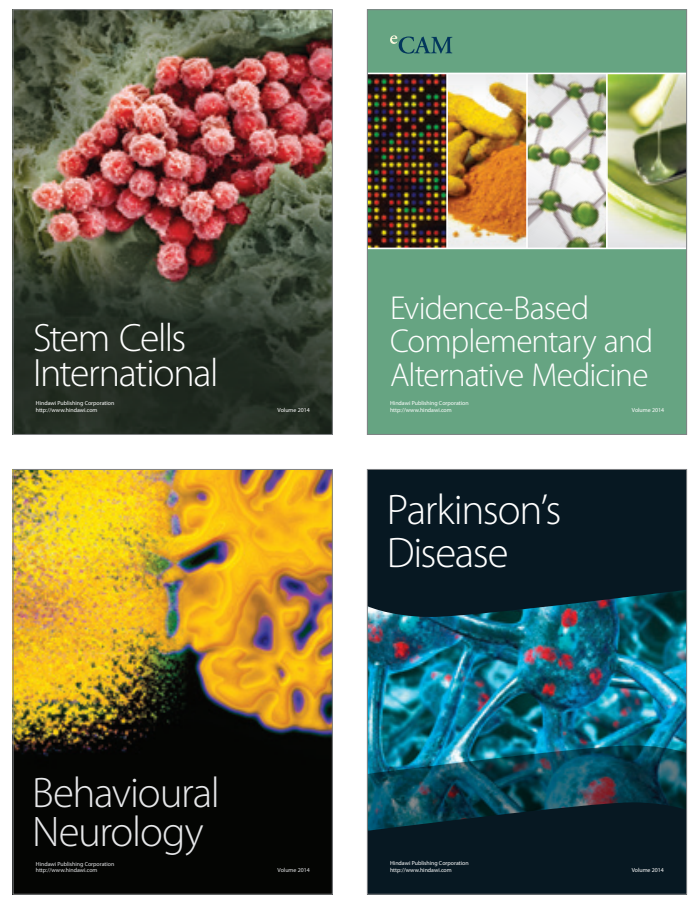
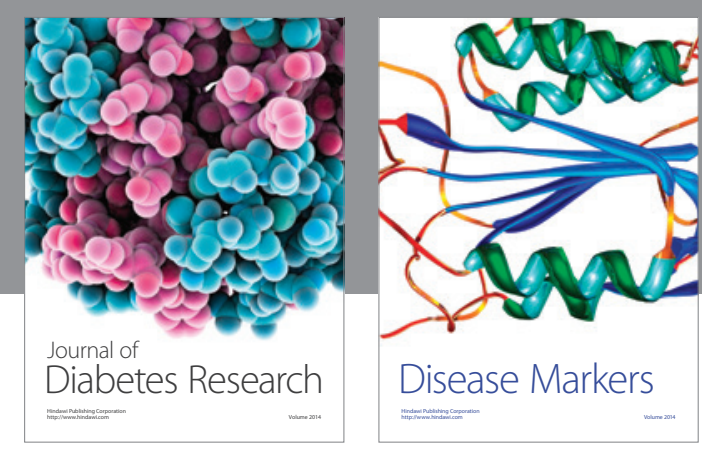

Disease Markers
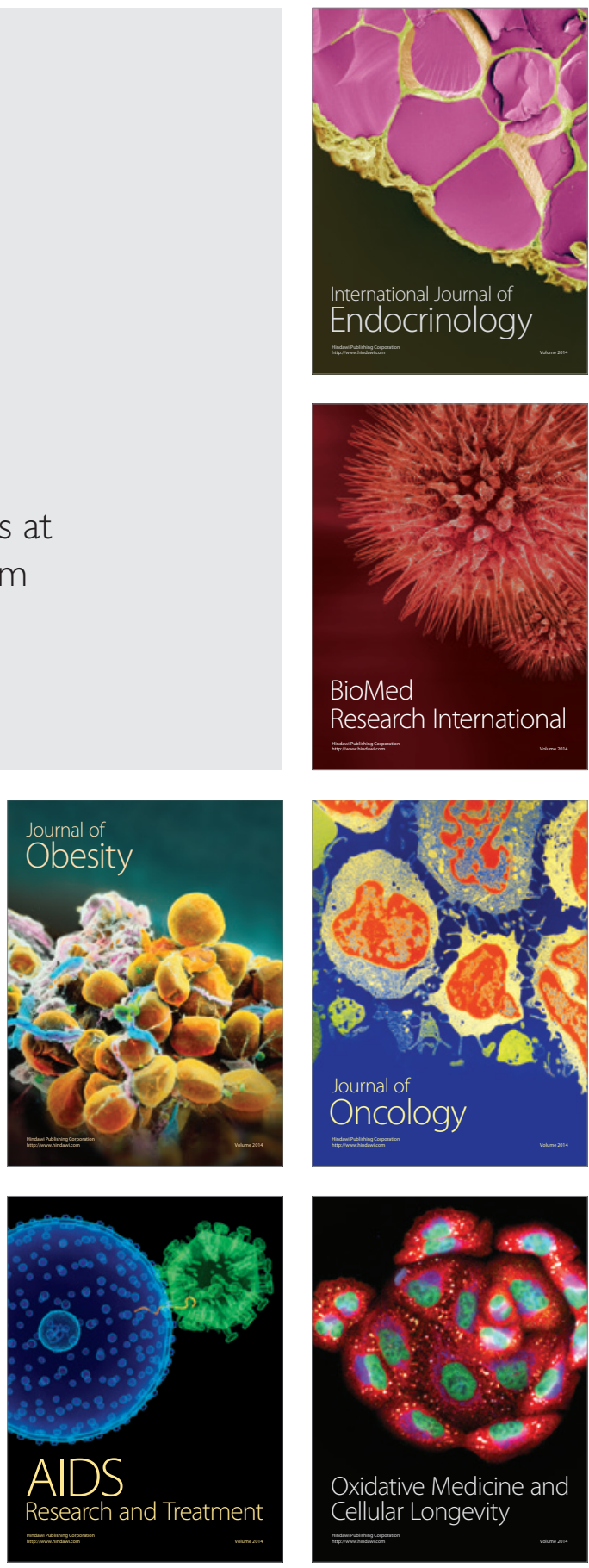